\title{
General decay for weak viscoelastic equation of Kirchhoff type containing Balakrishnan-Taylor damping with nonlinear delay and acoustic boundary conditions
}

\author{
Mi Jin Lee ${ }^{1}$, Jong-Yeoul Park ${ }^{1}$, and Jum-Ran Kang ${ }^{2}$ \\ ${ }^{1}$ Pusan National University \\ ${ }^{2}$ Pukyong National University
}

February 23, 2021

\begin{abstract}
In this paper, we consider the general energy decay for weak viscoelastic equation of Kirchhoff type containing BalakrishnanTaylor damping with nonlinear delay and acoustic boundary conditions. By introducing suitable energy and Lyapunov functionals, we establish the general decay estimates for the energy, which depends on the behavior of both sigma and g.
\end{abstract}

\section{Hosted file}

nonlinear time delay varying-2020-MMAS.pdf available at https://authorea.com/users/ 397512/articles/510365-general-decay-for-weak-viscoelastic-equation-of-kirchhoff-typecontaining-balakrishnan-taylor-damping-with-nonlinear-delay-and-acoustic-boundaryconditions

\section{Hosted file}

nonlinear time delay varying-2020-MMAS.tex available at https://authorea.com/users/ 397512/articles/510365-general-decay-for-weak-viscoelastic-equation-of-kirchhoff-typecontaining-balakrishnan-taylor-damping-with-nonlinear-delay-and-acoustic-boundaryconditions 